\title{
Complex Protective Coatings for Graphite and Carbon-Carbon Composite Materials
}

\author{
V. I. Zmij, S. G. Rudenkyi*, A. G. Shepelev \\ National Science Center "Kharkov Institute of Physics \& Technology", Institute of Material Science \& \\ Technology, Kharkov, Ukraine \\ Email: ${ }^{*}$ rudenkiys g@mail.ru
}

Received 10 June 2015; accepted 20 October 2015; published 23 October 2015

Copyright (C) 2015 by authors and Scientific Research Publishing Inc.

This work is licensed under the Creative Commons Attribution International License (CC BY).

http://creativecommons.org/licenses/by/4.0/

c) (i) Open Access

\section{Abstract}

The objective of this review is to present the results on the production techniques, process parameters and compositions of heat-resistant coatings for graphite and carbon-carbon composites. The data reported concern the resistance of such protective coatings in air at temperatures up to $2273 \mathrm{~K}$ and in the high-speed flows of oxidizing gas media taking place in the spacecraft equipment. Coatings of this type, generally, have a multilayer structure based on the refractory compounds such as carbides, borides, silicides of transition metals and oxides with a high melting temperature. An efficient heat-resistant coating for carbon-based materials should be composed of three layers from which each fulfills its own function. The paper presents a new complex method for formation of heat-resistant coatings on the carbon-based materials. The method combines the vacuum-activated diffusion saturation in the presence of a liquid-phase and self-propagating high-temperature synthesis (SHS) simultaneously.

\section{Keywords}

Carbon, Heat-Resistant Coatings, Diffusion Saturation

\section{Introduction}

Graphite and carbon-carbon $(\mathrm{C} / \mathrm{C})$ composite materials offer a diversity of unique high-temperature properties that makes them ideal candidates for various high-temperature structural applications, in particular, spacecraft engineering. Among different properties of carbon-based materials, the most frequently used are: hardening by heating to $\sim 2773 \mathrm{~K}$, high thermal stability, heat conductivity, and relatively low coefficient of thermal expansion. It should be noted, that $\mathrm{C} / \mathrm{C}$ composites, compared to graphite, have a higher resistance to thermal and mechan-

${ }^{*}$ Corresponding author.

How to cite this paper: Zmij, V.I., Rudenkyi, S.G. and Shepelev, A.G. (2015) Complex Protective Coatings for Graphite and Carbon-Carbon Composite Materials. Materials Sciences and Applications, 6, 879-888.

http://dx.doi.org/10.4236/msa.2015.610090 
ical impacts, ablation and electroerosion.

However, under conditions of high temperatures, even above $773 \mathrm{~K}, \mathrm{C} / \mathrm{C}$ composites reveal comparatively low oxidation resistance, which restricts to a great extent their wide application in different fields, particularly, in the high-temperature equipment.

At present, the problems of effective protection for carbon-based materials, being under conditions of different oxidizing media, are comprehensively discussed in the literature. A current state of this problem is under consideration in the review article [1]. The effective protection of $\mathrm{C} / \mathrm{C}$ composites against oxidation can be provided with taking into account the following: use of such materials as oxides, carbides, nitrides, borides, silicides and their various compounds; deposition methods and conditions; thickness and crack resistance of coatings; material designing limiting because of the chemical activity of material reinforcement components; new approaches to the choice of a heat-resistant coating material. Main requirements to the carbon composites are: atmospheric oxidation resistance, thermal impact resistance, humidity resistance, and high mechanical strength. The methods of carbon-based material stabilization are based on different approaches: multilayer coating deposition, formation of glass-forming or metallic coatings subjected to chemical transformations by thermal treatment, and glass-forming compound impregnation. In the above-mentioned review, one offers to use for carbon-based material protection the refraction metals such as $\mathrm{W}, \mathrm{Re}, \mathrm{Mo}, \mathrm{Nb}, \mathrm{Hf}, \mathrm{Ti}, \mathrm{Zr}$, their oxides, silicides, borides, carbides, nitrides and composites with these components.

\section{Basic Techniques of Protective Coating Deposition on Carbon-Carbon Composite Materials}

The methods, used for protective coating deposition on carbon-based materials, are:

-chemical vapor deposition (CVD method), in particular, with the use of metal-organic compounds (MOCVD);

-reaction chemical vapor deposition (RCVD method);

-plasma deposition;

-chemical modification of saturating material surface

-sol gel techniques of solution deposition;

-electrolytic and electrophoresis solution deposition;

-high-temperature salt solution deposition.

Composite coatings are produced using the CVD and plasma deposition methods with the use of blend powder, and the electrophoresis solution deposition.

\section{Heat-Resistant Coatings on Carbon-Based Materials}

\subsection{Coatings Containing Oxide Layers}

From the analysis of data reported it follows that the maximum operating temperatures of protective coatings on the carbon-based materials are $2273-2550 \mathrm{~K}$. The combined carbide-boride coatings are the most efficient, and the multilayer coatings possess the higher crack resistance.

As to the operating characteristics of protective coatings on carbon-based materials, they are much dependent of both the choice of coating elements and the formation method. Authors of [2] proposed to use $\mathrm{Al}_{2} \mathrm{O}_{3}$, as a material for protective coatings designed to operate at $1300^{\circ} \mathrm{C}$, in combination with low-melting borosilicate glass. They have formed the composite coating using the plasma deposition and slurry methods. The protective coating resistance was tested in the petrol postcombustion flow at temperatures ranging from $1273 \mathrm{~K}$ to $1473 \mathrm{~K}$ during $12 \mathrm{~h}$. The comparative test results show that the method offered can be used for the $\mathrm{C} / \mathrm{C}$ composite protection against the oxidizing medium influence and gas flow erosion.

\subsection{Multilayer Coatings}

In paper [3] it is proposed to use the $\mathrm{SiC}$ - and $\mathrm{Si}-\mathrm{MoSi}_{2}$ coatings to increase the oxidation resistance of carbonbased materials. To form the coating the liquid silicon was used for carbon impregnation with subsequent $\mathrm{MoSi}_{2}$ deposition by the slurry method. It has been noted that such a complex coating is capable to protect carbon during long time at $1673 \mathrm{~K}$.

The issues of theory and practice in developing reliable protective coatings for $\mathrm{C} / \mathrm{C}$ composites to be deposited on the heat-stressed construction units of hypersonic spacecrafts working in the oxygen-containing gas 
flows are discussed in paper [4]. Main sources of coating fracture under these conditions and criteria of their assessment are determined. The risk of base material oxidation under the coating is connected, first of all, with the presence of open pores and cracks in the coating. A new physical-chemical model of a heterophase coating is offered. By this model a series of materials have been developed, to form from them the layered coatings to deposit them on the refractory alloys and $\mathrm{C} / \mathrm{C}, \mathrm{C} / \mathrm{SiC}, \mathrm{SiC} / \mathrm{SiC}$ composites. The layered coatings can provide the efficient protection against the high-temperature gas corrosion and erosion in the wide temperature range from 300 to $2100 \mathrm{~K}$. The deposited microcomposite material self-organizes under high-temperature action into the multilayer multifunctional coating having low values of the catalytic activity, $K_{\mathrm{W}} \sim 3 \mathrm{~m} / \mathrm{s}$ and the sufficiently high radiation capacity $\varepsilon=0.7 \cdots 0.8$. The coating has a multilayer nanostructure with a layer thickness of 10 to $1000 \mathrm{~nm}$. A rapid self-healing of micro- and macrodefects in the material and coating, as well as, an efficient oxide film formation on the surface is provided. Paper [4] presents the test data for coatings on the samples of niobium-based alloys and carbon-based materials under conditions imitating the spacecraft entry into the dense atmospheric layers.

\subsection{Barrier Layers}

Analysis of materials-candidates to be used as barrier layers and protective coatings for $\mathrm{C} / \mathrm{C}$ composites is made in [5]. The article reports about theoretical and experimental investigations of promising barrier layers and heat-resistant composites providing an efficient protection of $\mathrm{C} / \mathrm{C}$ composites against high-temperature oxidation. Besides, authors consider typical peculiarities in the formation and fracture of protective coatings on carbon-based materials. It has been noted that at present the main method of carbon-based material protection against high-temperature oxidation is still the deposition silicon carbide coatings onto the material surface. Their oxidation protection properties are provided due to the formation of a $\mathrm{SiO}_{2}$-based gas-impermeable oxide film. Theoretically such coatings can protect the carbon-based material against oxidation in air at temperature to 2073 $\mathrm{K}$, but, above this temperature the protective film undergoes the fracture.

However, this theoretical limit for purely silicon-carbide coatings on the carbon-based materials is practically inaccessible as a result of the coating-substrate interaction and light-end product formation, which destruct the film, and because of the structure defects, in particular, porosity.

Furthermore, in [5] some fundamental problems of developing heat-resistant coatings for carbon-based material are discussed and possible ways of solving them are proposed. The choice of high-enthalpy compounds of transition metals from group IV as barrier layer components is substantiated. Different variants of protective layer formation on the compositions comprising carbon-based material and " $\mathrm{MeC}$ barrier layer" ( $\mathrm{Me}$ is $\mathrm{Ti}, \mathrm{Zr}$ or $\mathrm{Hf}$ ) are tested. Authors suppose that only the application of complex multi-layer protective coatings can provide an efficient protection of carbon-based materials against high-temperature oxidation at temperatures above 1973 $\mathrm{K}$. It is explained by the fact that any of the coatings on the carbon-based materials being under high-temperature oxidation is exposed to the action of two counter diffusion flows: oxidizing flow of oxygen atoms from the surface being oxidized and recovering flow of carbon atoms from the carbon base. The choice of structure and phase components of high-temperature coatings for the carbon-based materials is substantiated. All of them should be characterized by the maximum possible thermomechanical compatibility between themselves and the substrate to provide a smooth transfer of physical-mechanical properties from the carbon base to the coating surface. The contacting coating components should be compatible to a greater extent at operating temperatures, i.e. they should not very quickly enter into reactions accompanied by new phases. The compounds forming a barrier layer should have high melting temperatures and should be maximum inert to the carbon and compounds-components of the own protective layer at operating temperatures. The most preferable from the above stated point of view are carbides and borides of transition metals from groups IVa and Va, as well as, higher silicides of metals from group VI.

\subsection{Complex Coatings}

The methods applied for formation and investigation of carbon-silicide coatings on the carbon-based materials are presented in [6].

For protection of carbon-carbon composite materials against oxidation authors of [7] have proposed a two-layer coating: outer layer of $\mathrm{MoSi}_{2}$ and inner layer of $\mathrm{SiC}$. Phase composition and corrosion properties of the coating were investigated. It is noted that at $\mathrm{T}=1773 \mathrm{~K}$ the coating protects the $\mathrm{C} / \mathrm{C}$ composite against oxi- 
dation for 346 hours with the mass loss of $2.49 \mathrm{mg} / \mathrm{cm}^{2}$, and at $1903 \mathrm{~K}$ the coating resistance is 88 hours with the mass loss of $5.68 \mathrm{mg} / \mathrm{cm}^{2}$.

Oxidation of the $\mathrm{SiC} / \mathrm{ZrB}_{2}-\mathrm{SiC} / \mathrm{SiC}$ multilayer coating on the $\mathrm{C} / \mathrm{C}$ composite has been investigated in [8]. It is noted that in this study the coating was developed in order to extend the temperature range of $\mathrm{C} / \mathrm{C}$ composite application. The multi-layer coating was formed in three steps by the methods of cementation, slurry deposition and chemical vapor deposition. The coating obtained, composed of three layers with a total thickness of $\sim 150$ $\mu \mathrm{m}$, can protect the $\mathrm{C} / \mathrm{C}$ composite during more than 300 hours at $1173 \mathrm{~K}$ that is characteristic for $\mathrm{ZrB}_{2}$. The composite oxidation resistance at $1773 \mathrm{~K}$ is 217 hours due to the protective properties of the $\mathrm{SiO}_{2}-\mathrm{ZrSiO}_{4}$ film which is formed in the process of coating oxidizing.

\subsection{Coatings Obtained Using the Sol Gel Technique}

In paper [9] the investigation results on the multipurpose MAI D5 coating, designed for protection of highly heat-resistant materials, are discussed. Also there given are the results of tests on the thin heterophase coating designed for protection of products from carbon-bearing composites and alloys based on refractory metals against high-temperature gas corrosion and erosion. The coating was formed from the specially developed microcomposite powdered Si-Ti-Mo-B-Y material. A new approach was applied to create self-healing heterophase coatings. Under thermal effects of operating temperatures the structure and phase composition of the MAI D5 coating provide the rapid self-healing of defects on its surface and in the material base. This is reached due to the presence of silicon-containing eutectics promoting the accelerated recovering of the protecting amorphous silica layer consumed in the course of operation. This coating provides the $\mathrm{C} / \mathrm{C}$ protection against air oxidation at $\mathrm{T}=$ 2073 and $2273 \mathrm{~K}$ for $200 \mathrm{~s}$ and $20 \mathrm{~s}$ respectively.

The processes of protective coating formation on carbon fibers are investigated in [10]. There are studied the interface protective coatings, based on the refractory nanosized compounds of carbon bunches and ribbons. Possibilities of depositing thin layers composed of refractory oxides of aluminum, zirconium and silicon onto the continuous carbon fibers by the sol gel method are investigated. Two-layer coatings, composed of zirconium carbide and zirconium oxide, were deposited using the gas-transport chemical reactions. Morphological features, phase and elemental composition of coatings were investigated with the help of high-resolution X-ray phase electron microscopy analysis and qualitative energy dispersive analysis. It is shown that the refractory oxide coatings are uniformly distributed throughout the thickness and the length of single fibers. They have a good adhesion to the fiber, are not spalling, their thickness does not exceed $200-300 \mathrm{~nm}$. The oxide resistance of carbon-based materials with different-type coatings has been studied.

The coating formed of dispersion particles, designed for protection against the high-temperature oxidation of graphite and carbon-carbon composites, are discussed in [11]. It has been established that there are two main causes of deterioration in protective properties of coatings on graphite and carbon-carbon materials, namely, a weak adhesion between the coating and the substrate and coating cracking. It is possible to eliminate these problems by melting the slurry of oxidation-resistant materials on the $\mathrm{C} / \mathrm{C}$ surface and by forming laminar structures due to the reactions between the coating and the substrate. By this procedure the cracks in the coating also are healed. The cracks can be enclosed inside the phases, most frequently, in the course of metal carbide and silicide formation. In [11] one considers the coating with $\mathrm{Si}-\mathrm{Hf}-\mathrm{Cr}, \mathrm{Si}-\mathrm{Zr}-\mathrm{Cr}$ and $\mathrm{Si}-\mathrm{Ti}$ which provide the protection of carbon-based materials in the oxidizing media at $1873 \mathrm{~K}$.

The $\mathrm{C} / \mathrm{SiC} / \mathrm{Si}-\mathrm{Mo}-\mathrm{B} /$ glass-like multiphase oxidation protective coatings for $\mathrm{C} / \mathrm{C}$ composites are discussed in [12]. In this work the self-sealing multilayer oxidation coating composed of inner $\mathrm{C} / \mathrm{SiC}$ layer, intermediate Si-Mo-B layer and outer glass-like layer was prepared by the sintering of corresponding slurries. Analysis of the structure and phase composition was performed using the scanning electron microscopy (SEM) and X-ray diffraction methods. The isothermal resistance and heat shock of developed coatings were also investigated. The multilayer coating has had a high oxidation resistance under temperature variation conditions from the room temperature to $1873 \mathrm{~K}$, namely, 40 thermal cycles and 150 hours at $1873 \mathrm{~K}$.

\subsection{Gradient Coatings}

In [13] the oxide resistance of $\mathrm{C} / \mathrm{C}$ composites was increased by deposition of gradient coatings using the surface reactions. The gradient $\mathrm{ZrB}_{2}$ - $\mathrm{SiC}$ coatings at the interface with carbon were composed of the $\mathrm{ZrB}_{2}-\mathrm{SiC}$ layer and outer $\mathrm{ZrB}_{2}$-SiC-Si layer. The multilayer coating of $\sim 200 \mu \mathrm{m}$ thickness practically have not any cracks. 
The corrosion resistance of coatings in air was investigated at $1773 \mathrm{~K}$. The coating was resisting during $207 \mathrm{~h}$ with the mass loss of $(4.56 \pm 1.2) \times 10^{-3} \mathrm{~g} / \mathrm{cm}^{2}$, in addition a high-stable protective $\mathrm{ZrSiO}_{4}$, glass-like film was formed at its surface.

\section{Complex Method of Heat-Resistant Coating Formation by the Vacuum Activated Diffusion Saturation in the Presence of a Liquid Phase and SHS Process Simultaneously}

In [14] some features of the vacuum-activated diffusion saturation of $\mathrm{C} / \mathrm{C}$ composites, simultaneously with the self-propagating high-temperature synthesis (SHS) under action of liquid and gaseous media, were investigated. In this case the coatings were formed under synergetic conditions with simultaneous action of energy and mass flows. Thermodynamic analysis on the process of complex carbon-boron-silicide coating formation on the base of refractory metals, (tungsten, molybdenum, zirconium and hafnium) was performed. The coatings on the carbon-based materials were tested for heat-resistance and thermal stability at temperatures ranging from 1773 to $2173 \mathrm{~K}$.

\subsection{Vacuum Activated Diffusion Saturation}

In refs. [15]-[17] the peculiarities of a new method of vacuum-activated diffusion saturation of materials with different elements are under consideration. The protective coating formation by this method has some advantages compared with widely applied methods of coating formation in the closed containers with "fusible lock" where low-enthalpy halogenides, in particular, $\mathrm{NH}_{4} \mathrm{Cl}$ and $\mathrm{CCl}_{4}$, are used as an activator. The chlorides readily decompose with comparative ease at high temperatures and form chlorides of the saturating element in the reaction zone. As a result of disproportionation reactions these chlorides provide the corresponding coating formation. In the case of vacuum-activated diffusion saturation one uses, as an activator, high-enthalpy halogenides, in particular, sodium chloride. By this method the mechanism of halogenide formation from the saturating element is related with the surface ionization of activator vapors depending on its thermodynamic stability, as well as, on the similarity between the saturating element and corresponding halogen. A positive aspect of the method is the fact that the diffusion saturation process is realized in the vacuum that significantly decreases the level of substrate-and-coating alloying due to the embrittlement with interstitial elements. Besides, according to the Le Chatelier principle it is possible to influence on the displacement of chemical reaction equilibrium in the system under consideration and, consequently, to change the structure and properties of coatings being formed. As the system is quasi-opened, the activator, undergoing the recombination in the reaction zone, releases from it in the form of initial halogenide vapors and deposits on the cooled trap. It should be noted that, in fact, the method combines the gaseous-phase deposition and diffusion saturation because the formation of halogenides of saturating elements and their decomposition in the reaction zone occur sequentially. The advantage of the method consists in the fact that the coating deposition process, unlike the chemical vapor deposition, is realized completely under isothermality conditions, when the production process efficiency significantly increases as regards of both the coating material (halogenides of saturating elements) saving and the product yield increase in the process work volume. Moreover, by this method the coatings can be deposited on the irregular-shape products and hard parts. In general, the process of vacuum-activated diffusion saturation is high efficient, wasteless and nonpolluting.

\subsection{Complex Carbon-Boron-Silicide and Oxide Coatings}

The corrosion resistance of complex carbon-boron-silicide and oxide coatings on carbon-based materials in air at temperatures from 1773 to $2173 \mathrm{~K}$ has been investigated in [18] [19].

It should be noted once more feature of $\mathrm{C} / \mathrm{C}$ composites that complicates the deposition of efficient protective coatings, i.e. their high porosity. Peculiarities of the $\mathrm{C} / \mathrm{C}$ composite structure porosity, in particular, size distribution of pores, their penetrability for oxidizer molecules, open and closed porosity determine, in large measure, the material behavior in the oxidizing gaseous atmosphere. The oxygen-carbon interaction will take place not only on the outer surfaces but, also, in the pores and on the inner surfaces, as a result of oxidizer diffusion. The quantity of pores, their sizes and distribution in the sample volume are strongly dependent on the carbon-based material structure which, in turn, is determined, in a complicated manner, by the process parameters. Chemical 
vapor deposition of coatings on the carbon-based material surface by the method of thermal decomposition of metal-containing compounds and vacuum diffusion saturation occurs at the atomic level and, generally, repeats the surface relief and, practically, does not decrease the surface porosity [19] [20]. In this connection to protect the carbon-based materials against corrosion it is necessary to form on their surface a heat-resistant complex multicomponent and multilayer coating in which each of layers should implement its given function. The first inner layer should be solid, should decrease well the open porosity due to the high adhesion with the substrate and should have the coefficient of thermal expansion close to that of the carbon-based material, providing the decrease of stresses, which arise between the base and the coating. The second layer should have a high thermal stability, heat-resistance and should operate as a barrier decreasing the carbon- and coating component mass transfer to the interface boundaries. The outer heat-resistant layer should be composed of high-enthalpy oxides and should possess the self-healing properties. Similar coatings were investigated in [14] [18] [19] [21].

\subsection{Formation of Heat-Resistant Coatings by the Vacuum Activated Diffusion Saturation in the Presence of a Liquid Phase and SHS Process Simultaneously}

To develop an efficient heat-resistant coating on the carbon-based materials one should solve the problem of high-porosity elimination and to increase the rate of protective layer formation. For this the process of surface layer formation by the method of vacuum-activated saturation in the liquid-phase presence has been carried out simultaneously with the process of self-propagating high-temperature synthesis (SHS). The Ni-(Si, B) eutectic compositions were used as a liquid medium. The SHS process was realized with the use of thermit mixtures being the components of high-temperature protective coatings $\mathrm{W}-(\mathrm{Si}, \mathrm{B}, \mathrm{C})$ and $\mathrm{Hf}-(\mathrm{Si}, \mathrm{B}, \mathrm{C})$, formed on the substrate of carbon-based material, mainly, by the gaseous-phase condensation. The self-propagating high-temperature synthesis, as a method for production of new materials in the form of chemical compounds and coatings, is well-described in the literature, in particular, in [22]-[24]. However, the heterogeneous features of the SHS process, when the reactive components are in different aggregate states and isothermal reactions take place in the near-surface layer, currently are not studied. In this case it is supposed that the single components (carbon and tungsten), participating in chemical reactions during the protective coating formation, are in solid state while the rest components are in liquid or vapor state.

Recently a series of articles have been published in the literature [25]-[27]. There discussed are rather complicated problems of theory for thermomechanical kinetics of heterogeneous processes in the powder reactive systems. Generally, in the cases under consideration the processes occur under nonequilibrium conditions with a synergetic character of the energy-and-substance action on the system elements. For systems, such as these, the self-organization processes are characteristic.

The protective layer formation mechanism was studied by the method of thermodynamic analysis of possible chemical reactions between the system components [21]. For this purpose the analysis was performed, in particular, on the interaction of the gas-saturating medium, arising in the process of vacuum-diffusion activated boron-siliconizing in the presence of sodium chloride, with the slurry-layer components (W, Hf, Ni) and the substrate material. Analysis of the chemical reaction proceeding was made within the range of temperatures $\mathrm{T}=$ $1500-1650 \mathrm{~K}$ and under pressures $\mathrm{P}=1333-1.33 \mathrm{~Pa}$. During the sodium chloride interaction with silicon and boride, the chlorides of these elements are formed. The substrate saturation with silicon and boron occur when their lower chlorides enter into reactions of disproportionation [28] [29]. The temperature increase and pressure decrease in the reaction zone lead to the increase of the lower chloride part and activator efficiency. Chemical reactions, describing the interaction of silicon and boron monochlorides with hafnium, tungsten and carbon, as well as, the calculated values of adiabatic combustion temperature in the most probable chemical reactions are given in Table 1.

The calculated values of adiabatic combustion temperature are the rounded-off and slightly overestimated values, since the reference books do not give exact values of the corresponding temperature dependences of heat capacities $C_{\mathrm{p}}=f(T)$ in such a wide temperature range. It may be assumed that most of the reactions under consideration occur under conditions similar to the adiabatic ones. It is explained by the fact that the reaction zone takes place at the surface of carbon-based material having the comparatively low heat conductivity, and the heat transfer in the gaseous medium with decreased pressure is insignificant. In this case a local heating is possible that can stimulate the protective coating formation due to the accelerated diffusion of refractory elements which make the diffusion coating base [21]. 
Table 1. Gibbs free energy and degree of transformation $\alpha$ of probable chemical reactions in the $(\mathrm{NaCl}, \mathrm{SiCl}, \mathrm{BCl}$, $\mathrm{HfCl})-(\mathrm{W}, \mathrm{Ni}, \mathrm{C})$ system.

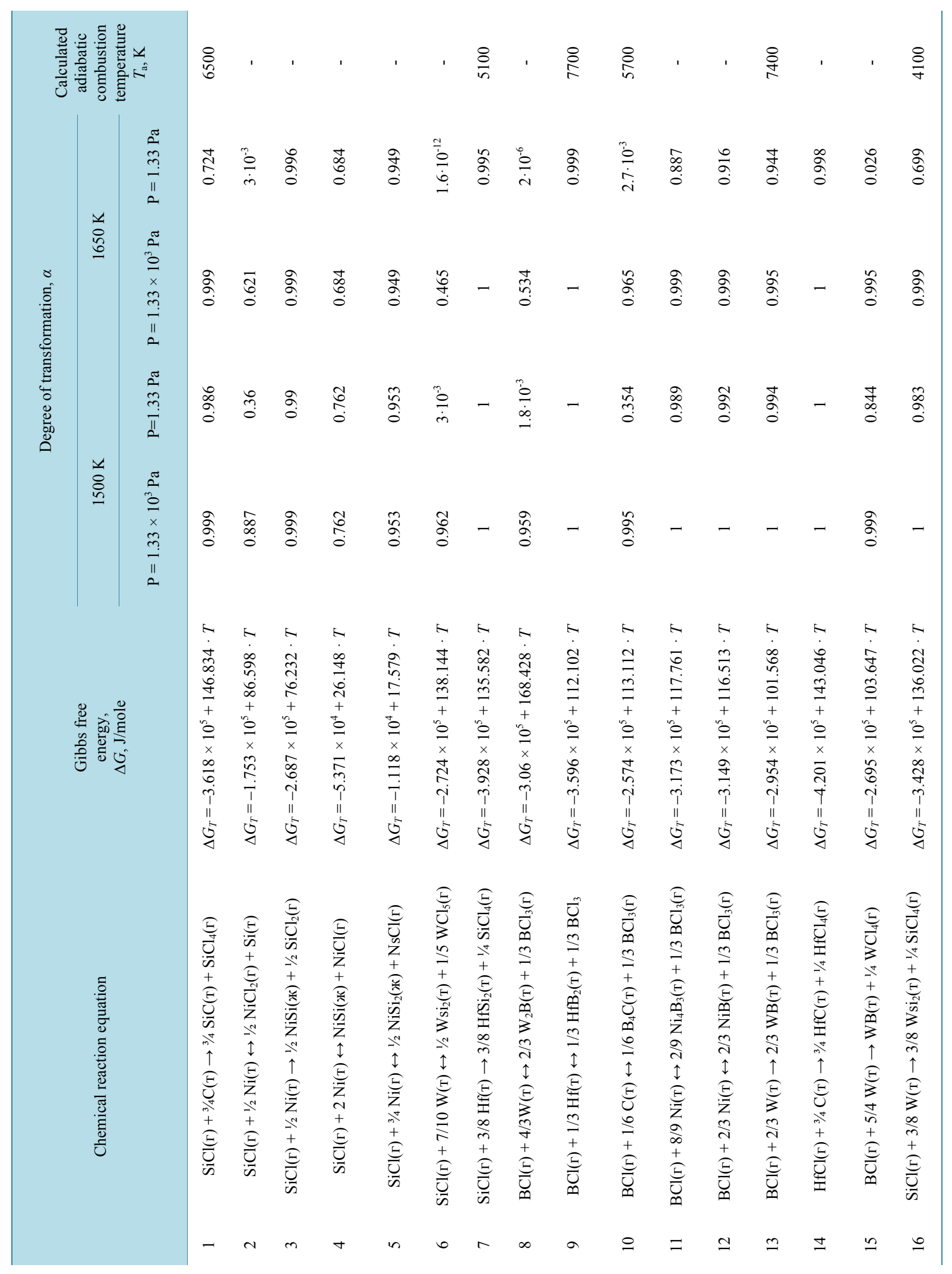


The experiments carried out in [21] were aimed to the deposition of above-mentioned protective coatings containing tungsten, hafnium, nickel, silicon and boron on the $\mathrm{C} / \mathrm{C}$ composites. For initial samples taken were cylindrical bars of graphite and $\mathrm{C} / \mathrm{C}$ composite $(8 \mathrm{~mm}$ diameter, $100 \mathrm{~mm}$ length). The coatings of $150 \mu \mathrm{m}$ thickness were deposited at temperature of $\sim 1573 \mathrm{~K}$ during about $15 \mathrm{~h}$. Figure 1 presents the microphotographies of $\mathrm{C} / \mathrm{C}$ composite samples: initial sample and coated sample. The complex coating is, mainly, composed of $\mathrm{SiC},\left(\mathrm{W}_{x} \mathrm{Ni}_{y}\right) \mathrm{Si}_{2}$ and $\mathrm{HfB}_{2}$. The heat-resistance tests of samples were carried out by the resistive heating in air within the temperature range from $1773 \mathrm{~K}$ to $2173 \mathrm{~K}$ (Table 2). The thermal spalling tests were carried out in the heating-curing mode at $1873 \mathrm{~K}$ during $3 \mathrm{~min}$ followed by the stopping and cooling-down during the same time. The samples were air-cured on average for $5 \mathrm{~h}$ at $2073 \mathrm{~K}$ and $1 \mathrm{~h}$ at $2173 \mathrm{~K}$ and in the same temperature regime on average of 50 thermal cycles.

\section{Conclusions}

An efficient heat-resistant coating on the carbon-carbon composite material should be a multilayer coating in which each of layers performs its function. A sublayer provides the coating adhesion with the substrate and a next layer serves as a barrier preventing a counter mass transfer of hydrogen and oxygen. These layers are composed of refractory carbide and boride. A protective layer consists usually of refractory compounds such as molybdenum-, tungsten-, hafnium-, and zirconium-silicides. An outer layer should be based on compounds such as aluminum-, silicon-, zirconium-, and hafnium-oxides.

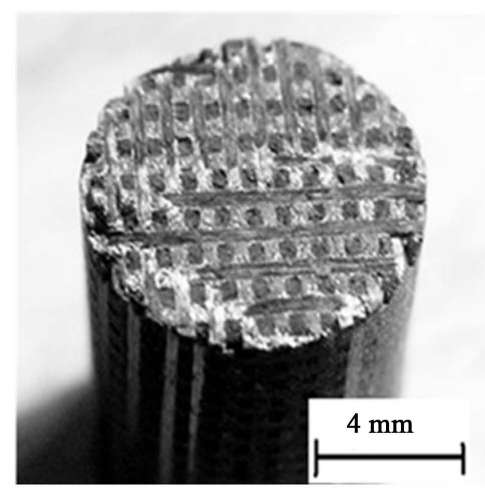

(a)

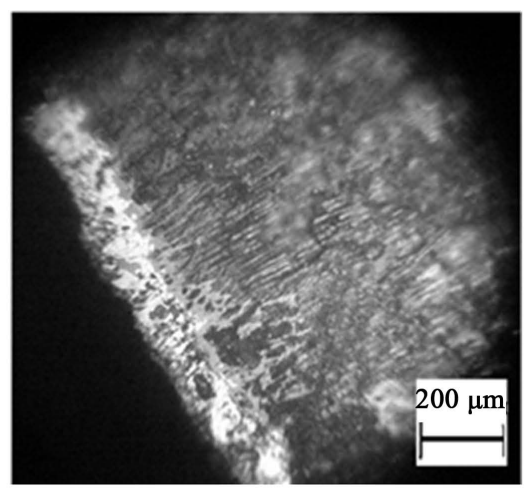

(b)

Figure 1. Microphotographies of $\mathrm{C} / \mathrm{C}$ composite samples: (a) initial sample and (b) coated sample.

Table 2. Heat resistance of complex carbon-boron-silicide coatings on carbon-based materials.

\begin{tabular}{cccc}
\hline \multirow{2}{*}{ Graphite sort } & Protective coating composition & \multicolumn{2}{c}{ Heat resistance } \\
\cline { 3 - 4 } APB & $\mathrm{SiC}+\left(\mathrm{W}, \mathrm{Co}^{2} \mathrm{Si}_{2}\right.$ & Test temperature, $\mathrm{K}$ & Time to rupture, $\mathrm{h}$ \\
\hline MПГ & $\mathrm{SiC}+(\mathrm{W}, \mathrm{Co}) \mathrm{Si}_{2}$ & 1773 & 15.0 \\
$\mathrm{C} / \mathrm{C}$ & $\mathrm{SiC}+\mathrm{HfB}_{2}+\mathrm{MoSi}_{2}$ & 1773 & 21.0 \\
$\mathrm{M \Pi \Gamma}$ & $\mathrm{SiC}+\mathrm{HfB}_{2}+\mathrm{MoSi}_{2}$ & 1773 & 32.0 \\
$\mathrm{APB}$ & $\mathrm{SiC}+\mathrm{HfSi}_{2}+\mathrm{MoSi}_{2}$ & 1973 & 20.5 \\
$\mathrm{APB}$ & $\mathrm{SiC}+\mathrm{HfC}+\mathrm{MoSi}_{2}+\left(\mathrm{ZrO}_{2}+\mathrm{SiO}_{2}\right)$ & 2073 & 8.0 \\
$\mathrm{C} / \mathrm{C}$ & $\mathrm{SiC}+\mathrm{TiC}+\mathrm{HfB}_{2}+\mathrm{MoSi}_{2}$ & 2073 & 6.0 \\
$\mathrm{APB}$ & $\mathrm{ZrC}+\mathrm{MoSi}_{2}$ & 2073 & 7.0 \\
$\mathrm{APB}$ & $\mathrm{TiC}+\mathrm{MoSi}_{2}$ & 2073 & 3.0 \\
$\mathrm{M \Pi \Gamma}$ & $\mathrm{SiC}+\mathrm{TiC}+\mathrm{HfB}_{2}+\mathrm{WSi}_{2}$ & 2073 & 5.0 \\
\hline
\end{tabular}


In conclusion, it should be noted that a new method of multipurpose protective coating deposition on the structural carbon-based material is developed. A positive characteristic of this method is the fact that under isothermal conditions the activator transforms the diffusant from the solid state into the gaseous phase, namely, halogenide. This gas significantly increases the rate of diffusant transformation to the substrate, and the liquid media, in turn, accelerates the diffusion saturation in consequence of coating element dissolution in them. The selfpropagating high-temperature synthesis provides the introduction into the reaction zone of termite mixtures which can increase the temperature up to $3273 \mathrm{~K}$ and more as a result of exothermal reactions due to the heat release in the near-surface layer of the substrate being coated. This effect will promote the acceleration of the process of high-temperature protective coating formation on the carbon-based materials.

\section{References}

[1] Tkachenko, L.A., Shaulov, A.Yu. and Berlin, A.A. (2012) Protective Heat-Resistant Coatings for Carbon-Base Materials. Neorganicheskiye materialy, 48, 261-271. (In Russian)

[2] Babin, S.V. and Khrenov, V.V. (2011) Devepopment and Investigation of Protective Coating for Carbon-Carbon. Nauchno-tekhnicheskij vestnik Povolgya, 3, 49-53. (In Russian)

[3] Zhao, J., Guo, Q.N., Shi, J.L., Zhai, G.T. and Lin, L. (2006) SiC-Si-MoSi ${ }_{2}$-Oxidation Protective Coating for Carbon-Carbon Composites. Surface and Coatings Technology, 201, 1861-1865. http://dx.doi.org/10.1016/j.surfcoat.2006.03.019

[4] Terentyeva, V.S. and Zhestkov, B.E. (2009) Multipurpose High-Temperature Coating on Refractory Alloys and C/C Composites. Khimicheskaya fizika, 28, 64-70. (In Russian)

[5] Kasatkin, A.V. and Andryushin, S.G. (2011) Analysis of Promising Materials for Use as a Barrier Layers and Protective Coatings for Carbon-Carbon Composites. Korroziya: Materialy, zashchita, 6, 1-9. (In Russian)

[6] Kasatkin, A.V., Terent'yeva, V.S., Andryushin, S.G. and Yeryomina, A.I. (2004) Diffusion Carbide-Silicide and Carbide-Boride Silicide Coatings on Carbon-Base Materials. Aviakosmicheskaya Tekhnika i Tekhnologiya, 2, 30-37. (In Russian)

[7] Huang, J.-F., Wang, B., Li, H.-J., Liu, M., Cao, L.-Y. and Yao, C.-Y. (2011) A MoSi 2 /SiC Oxidation Protective Coating for Carbon/Carbon Composites. Corrosion Science, 53, 834-839. http://dx.doi.org/10.1016/j.corsci.2010.11.024

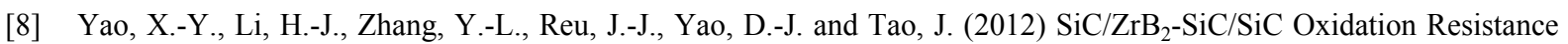
Multilayer Coating for Carbon/Carbon Composites. Corrosion Science, 57, 148-153. http://dx.doi.org/10.1016/j.corsci.2011.12.023

[9] Zhitkov, B.E. and Terentyeva, V.S. (2010) Investigation of Multipurpose MAI D5 Coating Designed for Especially-High-Resistant Materials. Metally, 1, 39-48.

[10] Baklanova, N.I., Zima, T.M., Titov, A.T., Isayeva, N.V. and Solntsev, S.S. (2006) Protective Coatings for Carbon Fiber. Inorganic Materials, 42, 823-829. (In Russian) http://dx.doi.org/10.1134/S0020168506070107

[11] Joshi, A. and Lee, J.S. (1997) Coatings with Particulate Dispersions for High Temperature Oxidation Protection of Carbon and C/C Composites. Composites Part A, 28, 181-189. http://dx.doi.org/10.1016/S1359-835X(96)00111-X

[12] Zhang, Y.-L., Yao, H.-J., Li, K.-Z. and Zhang, S.-Y. (2011) C/SiC/Si-Mo-B/Glass Multilayer Oxidation Protective Coating for Carbon Composites. Corrosion Science, 53, 2075-2079. http://dx.doi.org/10.1016/j.corsci.2011.02.024

[13] Reu, X.R., Li, H.J., Chu, Y.H., Li, K.Z. and Fu, Q.G. (2014) ZrB $\mathrm{Zr}_{2}$ SiC Gradient Oxidation Protective Coating for Car-

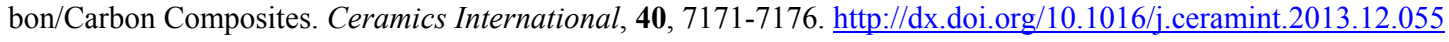

[14] Zmij, V.I. (2013) High-Temperature Protective Coatings on Carbon-Base Materials. Poroshkovaya Metallurgiya, 7/8, 85-92. (In Russian)

[15] Zmij, V.I. and Rudenkyi, S.G. (2010) Reaction-Activated Diffusion and Vacuum Coatings. NSC KIPT, Kharkov, 158 p.

[16] Zmij, V.I., Rudenkyi, S.G. and Kunchenko, V.V. (2011) Peculiarities of Activated Chemical-Thermal Material Treatment. Problems of Atomic Science and Technology, No. 2 Series: Radiation Damage Physics and Radiation Materials Science, Issue 97, 155-158.

[17] Zmij, V.I., Kartmazov, G.N. and Rudenkyi, S.G. (2012) Technique of Article Surface Diffusion Saturation. Patent of Ukraine No 98074. (In Russian)

[18] Zmij, V.I., Kartmazov, G.N., Kartsev, N.F. and Rudenkyi, S.G. (2006) Carbon-Boron-Silicide and Oxide Composite Coatings on Carbon/Base Materials. Poroshkovaya Metallurgiya, 3/4, 21-27. (In Russian)

[19] Zmij, V.I., Kartsev, N.F., Kovtun, N.V. and Rudenkyj, S.G. (2001) Investigation of the Carbon-Boron-Silicide HeatResistance Coating Formation on Carbon-Base Materials. Sbornik: Collected Articles "Temperature Resistant Func- 
tional Coatings", Tula, 15-17 May 2001, 72-79. (In Russian)

[20] Palatnik, L.S., Cheremskoj, P.G. and Fuks, M.Y. (1982) Pores in Films. M. "Ehnergoizdat”, 216p. (In Russian)

[21] Zmij, V.I., Kartmazov, G.N. and Rudenkyi, S.G. (2009) Complex Temperature-Resistant Protective Coating on Carbon-Carbon Composites. Fizika i khimiya stekla, 35, 58-63.

[22] Merzhanov, A.G. and Borovskaya, I.P. (1972) Self-Propagating High-Temperature Synthesis of Refractory Melting Inorganic Compounds. Doklady Akademii Nauk SSSR Khimiya, 204, 366-369. (In Russian)

[23] Kogan, Y.D., Sereda, B.P. and Kastogorov, E.P. (1994) Cromium Plated Coating Formation under SHS Conditions. Metals Science and Thermal Treatment of Metals, No. 3, 8-12.

[24] Gordienko, S.P. (1999) Thermodynamic Analysis of Titanium-Boron Carbide Interaction in the Self-Propagating HighTemperature Synthesis Mode. Poroshkovaya Metallurgiya, 3/4, 72-76.

[25] Skorokhod, V.V. and Solntsev, V.P. (2009) Formation of Bases for Thermochemical Kinetics of Heterogenous Processes in Powder Reactive Systems. Poroshkovaya Metallurgiya, 7/8, 48-50. (In Russian)

[26] Solntsev, V.P., Skorokhod, V.V., Baranov, V.L. and Solntseva, T.A. (2010) On the Mechanism of Spontaneous Space-Time Arranged Structure Formation in the Powder Reactive Systems by Contact Melting of Components. Dopovidi Natsional'noyi Academii Nauk Ukrainy, 3, 105-110. (In Ukraine)

[27] Solntsev, V.P. and Skorokhod, V.V. (2009) Thermal-Kinetic Model and Mechanism of the Reaction Interaction Initiated by the Peritectic Melting. Dopovidi Natsional'noyi Academii Nauk Ukrainy, 11, 91-97. (In Ukraine)

[28] Zmij, V.I. and Ruden'kyj, S.G. (1998) Peculiarities of Vacuum-Activated Diffusion Saturation of Metals: Thermodynamics, Mechanism, Kinetics. Metallofizika i novejshie tekhnologii, 20, 69-75. (In Russian)

[29] Rudenkyi, S.G. (2014) Physical \& Engineering Basis of the Vacuum-Activated Method of Multipurpose Coating formation on the Metallic and Carbon-Based Materials. Doctoral Thesis, Institute of Electrophysics and Radiation Technologies NAS of Ukraine, Kharkov. 